\title{
Polymer Coatings for Protection of Wood and Wood-Based Materials
}

\author{
Tamara V. Sakhno', Nikolay N. Barashkov², Irina S. Irgibaeva ${ }^{3}$, S. V. Pustovit ${ }^{4}$, \\ Yuriy E. Sakhno 5 \\ ${ }^{1}$ Poltava Department of Academy of Sciences of Technological Cybernetics of the Ukraine, Poltava, Ukraine \\ ${ }^{2}$ R\&D, Micro-Tracers, Inc., San Francisco, CA, USA \\ ${ }^{3}$ Department of Chemistry, Eurasian National University, Astana, Kazakhstan \\ ${ }^{4}$ Institute of Information and Innovative Technologies Poltava State Agrarian Academy, Poltava, Ukraine \\ ${ }^{5}$ Poltava Institute of Economics and Law at the University "Ukraine", Poltava, Ukraine \\ Email: Nikolay@microtracers.com
}

Received 21 October 2015; accepted 8 April 2016; published 11 April 2016

Copyright (C) 2016 by authors and Scientific Research Publishing Inc.

This work is licensed under the Creative Commons Attribution International License (CC BY).

http://creativecommons.org/licenses/by/4.0/

(c) †) Open Access

\begin{abstract}
Three major types of protective coating of wood and wood-based materials have been considered. These three types include the coatings based on carboxyl-containing water-soluble polymers which are easily cross-linked by inorganic salts or $\mathrm{OH}$-containing compounds, pH-sensitive coatings and polymer multi-layer structures. First of three mentioned approaches allows affecting permeability and enhancing the prevention the loss of water from the surface of wood to its surrounding. The advantage of the second approach is its ability to vary and purposely adjust the polymer composition and the number and distribution of - $\mathrm{COOH}$ groups in the chain which make the originally water-soluble polymers completely insoluble. The strong feature of the third approach which includes broad use of hydrogen-bonded films produced by layer-by-layer self-assembly is the possibility of manipulation of coatings stability after construction.
\end{abstract}

\section{Keywords}

Protective Coatings, Polymer Films, pH-Sensitivity, Water-Soluble Polymers, Hydrogen Bonds, Self-Assembly

\section{Introduction}

The search for new methods of the treatment of wood and other wood-based materials for protection against de-

How to cite this paper: Sakhno, T.V., Barashkov, N.N., Irgibaeva, I.S., Pustovit, S.V. and Sakhno, Y.E. (2016) Polymer Coatings for Protection of Wood and Wood-Based Materials. Advances in Chemical Engineering and Science, 6, 93-110. 
cay is very important goal. A piece of timber, due to the manner of its formation, possesses anisotropic structure which influences its properties and behavior. Compared to competitive cladding materials like metals and plastics materials, it has a number of major disadvantages which tend to counteract the advantages of strength, lightness, low thermal expansion and desirable aesthetic features [1].

To overcome and minimize these disadvantages a number of specific problems exist: 1) the wood must be protected against degrading environmental factors (namely, moisture cycling, photodegradation and biological attack); 2) the dimensional stability with respect to moisture cycling must be improved; 3) photodegradation due to sunlight must be minimized; 4) the resistance to biological attack (fungus) must be improved; 5) the adhesion of protective and decorative coatings must be improved; and 6) extractives which adversely affect protective and decorative properties of coatings must be sealed within the wood. Paint, shellac, epoxies, or urethanes are applied to the surfaces resulting in protection which lasts a few seasons before the need arises to scrape and sand the old protective surface and repeat the coating applications [2].

Damage often results to the original coating from the shallow penetration and sealing effect of applications made by brush, roll-on or spray. The cellular resin structure of wood tends to cause a chemical migration in the wood when thermal expansion stresses, such as hot and cold weather conditions, are imposed. During the warm weather, the expansion stresses cause the coatings to expand as a result of the forces imposed by the wood's cellular resins. At colder weather conditions, the contraction stresses cause the coatings to crack and peel, allowing moisture, acid rain and pollutant intrusion to cause the coatings to lift off the structures when freeze-thaw cycles occur. Moisture and pollutant absorption into the wood fibers accelerates decay. It is possible to assume that so far the nature of additives used for protection of wood products from decay and insect attack, as well as protective coating on the surface of the wood has not been optimized properly [3] [4].

Considering ecological aspects of choosing paint or coating for office furniture, for example, it is important to remember how paint (coating) ingredients have impacts on environmental and social responsibility that reach beyond just unpleasant odors. Paints can be made out of recycled, natural, or bio-based content. Although the customers won't find an ingredients label on most paint cans, companies are starting to divulge more information about their formulas because it impacts corporate social and ecological responsibility.

Leading chemical companies, such as Dow Chemicals which has 191 Manufacturing facilities in 38 countries and revenues about 30 billions of dollars per year are actively looking for new methods of wood protection [5].

Another large company Kelly-Moore Paints pioneered the concept of recycling paint about 15 years ago and currently offer an "e-coat" which uses 50\% recycled paint and 50\% new stock [6]. They also offer a zero-VOC (volatile organic compound) paint. Kelly-Moore’s eco-friendly lines have earned recognition and several certifications.

One more aspect of eco-friendliness is minimizing concentration of harmful components in processing wastewater which is generated during production of water dilutable protective and decorative paints for wooden surfaces [7]. This wastewater often contains all components of parent paints but only in significant dilution [8]. Majority of such components include inorganic compounds, such as carbonate of calcium and magnesium, barium sulfate, silica, mica, silicates, talk kaoline, and titanium dioxide, as well as organic derivatives, including, defoaming agents, surfactants, thickeners, siccatives, and pigments [9]-[11].

Analysis of the literature related to the application of protective coating shows that there are three promising approaches to the creation of materials with desirable properties:

1. Coatings based on carboxyl-containing water-soluble polymers which are easily cross-linked by inorganic salts or OH-containing compounds;

2. pH-sensitive coatings;

3. Polymer multi-layer structures.

Below the authors are going to consider the basics of three types of materials and analyze their advantages and disadvantages in terms of feasibility for proposed application.

\section{Films Based on Cross-Linked Carboxyl-Containing Polymers}

Coating based on polyacrylic and polymerthacrylic acids, as representatives of carboxyl-containing watersoluble polymers which are easily crosslinked by inorganic salts, have been studied numerous times for last 50 60 years [12]-[18]. Thus, in series of publications [12]-[14] it was found that polyacrylic acid is losing its solubility in water as a result of interaction with salts of copper (II). Entropy and enthalpy changes in complexation reactions between polyacrylic acid (PAA) and copper (II) were studied by measuring temperature dependence of 
the equilibrium constants. It appears that, as in case of other chelation reactions, the main contribution to the complex stability is that of the entropy.

Paper [15] describes the ionic crosslinking of PAA membranes for possible applications in dialysis and reverse osmosis. The technique consists of casting a film of PAA neutralized with sodium hydroxide, followed by immersion in appropriate metal salts (aluminum, zinc, and chromium salts). A qualitative rate model has been developed to guide this synthesis. Since both metal cations and protons in solution compete for the carboxylic acid sites, acid-base properties of the metal and polycarboxylic acid appear to be important for successful membrane formation. Crosslinking agents such as the $\mathrm{Zn}^{2+}$ and $\mathrm{Cr}^{3+}$ salts were tried but were not as successful as the $\mathrm{Al}^{3+}$ salts.

Detailed study of influence of different metal cations on crosslinking PAA films is presented in paper [16]. Table 1 lists these cations — and those that failed to cross-link the film — by atomic number. It was found that in order for a metal cation to cross-link a PAA film, at least two of the ligands in the inner coordination sphere of the metal cation must be replaced by carboxylate groups from PAA. The authors proposed to use the PAA films cross-linked with metal cations in photolithography. They reported that patterned by metal cations PAA films act as an ion-exchange resin that allows one cation to be exchanged for another. Also, reduction of these metal cations generates nanoparticles within a patterned polymer matrix. It was discovered that there is an interesting possibility to etch cross-linked PAA films by immersion them in $0.5 \mathrm{M}$ aqueous solution of EDTA $(\mathrm{pH}=8.2)$.

Another original application for PAA cross-linked with ferric chloride is proposed in paper [17], where waterinsoluble gel PAA-FeCl ${ }_{3}$ (molar ratio 2:1) is successfully tested for blocking of microscopic channels in tooth dentin with a purpose decrease the fluid permeability and protect against tooth decay.

In the authors' opinion the crosslinking PAA films with metal cations should be considered as one of the promising methods to affect permeability and enhance the prevention the loss of water from the surface to its surrounding.

Another promising approach for decreasing permeability of PAA film is related to crosslinking interactions between the proton-donating pendent $\mathrm{COOH}$ groups in PAA molecules and polar $\mathrm{OH}$ groups [18]-[21]. It has been reported [18] that the films of PAA becomes insoluble when reacted with glycerol or other polyhydric alcohols. According to [19], the reaction between PAA and hydroxyl-containing compounds, such as ethylene glycol can lead to the network structure, which is insoluble in water. More details regarding such an interaction

Table 1. Metal salts that cross-link a film of PAA and that fail to do so ${ }^{\text {a) }}[16]$.

\begin{tabular}{|c|c|}
\hline Cross-linking & Non-cross-linking \\
\hline $\mathrm{Al}\left(\mathrm{NO}_{3}\right)_{3}$ & $\mathrm{~B}(\mathrm{OH})_{3}$ \\
\hline $\mathrm{CaCl}_{2}$ & $\mathrm{NaCl}$ \\
\hline $\mathrm{TiBr}_{4}$ & $\mathrm{NaOH}$ \\
\hline $\mathrm{TiI}_{4}$ & $\mathrm{MgSO}_{4}$ \\
\hline $\mathrm{MnCl}_{2}$ & $\mathrm{KCl}$ \\
\hline $\mathrm{NiSO}_{4}$ & $\mathrm{NiF}_{4}$ \\
\hline $\mathrm{NiCl}_{2}$ & $\mathrm{CrCl}_{3}$ \\
\hline $\mathrm{Cu}(\mathrm{OAc})_{2}$ & $\mathrm{~K}_{4} \mathrm{Fe}(\mathrm{CN})_{6}$ \\
\hline $\mathrm{ZnCl}_{2}$ & $\mathrm{~K}_{3} \mathrm{Fe}(\mathrm{CN})^{6}$ \\
\hline $\mathrm{Zn}(\mathrm{OAc})_{2}$ & $\mathrm{NaPdCl}_{4}$ \\
\hline $\mathrm{ZrCl}_{4}$ & $\mathrm{CsCl}$ \\
\hline $\mathrm{ZrO}\left(\mathrm{NO}_{3}\right)_{2}$ & $\mathrm{AuCl}_{3}$ \\
\hline $\mathrm{Pd}\left(\mathrm{SO}_{4}\right)$ & $\mathrm{NaAuCl}_{4}$ \\
\hline $\mathrm{AgNO}_{3}$ & $\mathrm{Na}_{3} \mathrm{AuCl}_{4}$ \\
\hline $\mathrm{BaS}$ & $\mathrm{UO}_{2} \mathrm{SO}_{4}$ \\
\hline \multicolumn{2}{|l|}{$\mathrm{BaCl}_{2}$} \\
\hline \multicolumn{2}{|l|}{$\mathrm{La}\left(\mathrm{NO}_{3}\right)_{3}$} \\
\hline \multicolumn{2}{|l|}{$\mathrm{GdCl}_{3}$} \\
\hline \multicolumn{2}{|l|}{$\mathrm{Ho}\left(\mathrm{NO}_{3}\right)_{3}$} \\
\hline \multicolumn{2}{|l|}{$\mathrm{Pb}(\mathrm{OAc})_{2}$} \\
\hline $\mathrm{UO}_{2}(\mathrm{OAc})_{2}$ & \\
\hline
\end{tabular}

${ }^{\mathrm{a}}$ Films of PAA on a silicon wafer were immersed in either a $1 \mathrm{M}$ or a saturated solution of each metal salt for 1 minute. The films were subsequently rinsed with water $(\mathrm{pH} \approx 7)$ and dried with a stream of $\mathrm{N}_{2}$. Successfully cross-linked PAA films remained intact on the wafer; unsuccessful films dissolved. 
can be found in paper [20] where the authors studied the crosslinking between PAA and gelatin at different $\mathrm{pH}$ and pointed out that there are three kinds of cross-linking for polymer chains: one is the cross-linking between acrylic acid chains, another is the cross-linking between gelatin chains, and the third is the cross-linking between acrylic acid and gelatin. Owing to simultaneous cross-linking, the three kinds of chains interpenetrate and entangle, which results in the formation of an interpenetrating network structure in poly(acrylic acid)/gelatin hybrid [21].

\section{Regulation of the Flow of Chemicals between the Surface and Its Surroundings with pH-Sensitive Polymers}

Alkali-thickenable and alkali-soluble polymers are essentially high molecular weight materials containing pendant carboxyl groups in the polymer chain the salts of which swell or dissolve in water [22]. Properties may be varied by adjusting the polymer composition and the number and distribution of --COOH groups in the chain. Emulsions of such polymers have the unique advantage of being thick enable in situ, and can thus be stored and handled as low viscosity fluids until such time as their thickening property is to be utilized. They have found application for example in emulsion, paints and latex compounds for carpet sizing.

Resins of this type can be prepared by copolymerizing vinyl acetate with maleic anhydride [22], a monoalkyl ester of maleic acid [23] or crotonic acid [24]. Such copolymers are useful in certain adhesive and other applications where removability by aqueous alkali is required [22] and, in the non-aqueous state, as hair spray composition [25]. A possible disadvantage of vinyl acetate-crotonic acid copolymers which are otherwise particularly suitable is that they are generally of low molecular weight, due to the chain transfer property of crotonic acid in free-radical polymerization; additionally, most vinyl acetate copolymers are readily hydrolyzed by aqueous alkali [26].

Copolymerization of methylacrylate esters with methacrylic acid in aqueous emulsion systems is beneficial compared to copolymerization with acrylic acid due to the similar reactivity of methylacrylate esters and methacrylic acid. With methyl methacrylate, for example, $97 \%$ of the methacrylic acid introduced has been found to have copolymerized [27].

Detailed study of copolymerization of methylacrylate esters, such as methyl methacrylate (MMA), ethyl methacrylate (EMA) and n-butyl methacrylate (BMA) with methacrylic acid in aqueous emulsions has been described in paper [22]. Table 2 shows the composition which was used for process of copolymerization. According to this process, the water phase, contained in a one liter glass flask, was purged with nitrogen. At a temperature of $18^{\circ} \mathrm{C}-20^{\circ} \mathrm{C}$ the mixture of monomers, dodecyl mercaptan, ferric chloride, sodium persulfate and sodium metabisulfite, were added with stirring. Agitation was continued throughout at such a rate as to ensure continuous uniform mixing of the ingredients. The temperature rose rapidly to about $80^{\circ} \mathrm{C}$ and was maintained at this temperature for $30 \mathrm{~min}$. The emulsion was cooled down, its $\mathrm{pH}$ adjusted to $4.4-4.5$ with $20 \%$ aqueous sodium hydroxide and filtered through 400 mesh nylon. Conversions of monomer to polymer were greater than $98 \%$.

Table 2. Components of the composition for emulsion copolymerization [22]. The polymer emulsions were prepared to the following basic formula: Parts by weight

\begin{tabular}{cc}
\hline Monomers & Parts by weight \\
Dodecyl mercaptan & 100.00 \\
Polyoxyethylene (4 - 5) monolaurate & 0.20 \\
Sodium dodecyl sulfate & 1.00 \\
Sodium bicarbonate & $1.00-3.00$ \\
Sodium sulfate & 0.12 \\
Ferric chloride (to 5 ppm Fe on monomer wt) & 0.50 \\
Sodium persulfate & \\
Sodium metabisulfite & 0.24 \\
\hline
\end{tabular}


It was found [22] that an increase in the quantity of surfactant in emulsion polymerization usually results in a decrease in diameter of the polymer particles, often in inverse proportion to the surfactant: monomer ratio. For series which is shown in Figure 1, for given copolymer the particles size in the emulsion state showed a similar reduction with increase of sodium dodecyl sulfate concentration. Figure 1 shows as well that the quantity of acid comonomer also had a marked effect on the particle size, increase in methacrylic acid resulting in an initial slight reduction followed by an increase in particle diameter.

On raising the $\mathrm{pH}$ of an alkali-thickenable emulsion, the viscosity could increase by any one of three different mechanisms [22]:

(a) Solubilization of the polymer by forming its salt.

(b) Swelling of the particle with absorbed water.

(c) The electroviscous effect.

The solubility of a polymer depends on the concentration of carboxyl groups in relation to the hydrophobicity of the polymer; attached surfactants can have a similar effect [28] [29] to copolymerized acid. For a given concentration of polymer, a smaller particle size will mean that the area of the discrete phase in contact with the continuous phase will be greater than for a larger particle size. This results in a higher emulsion viscosity. At the limit, when the particle is identical with the polymer molecule, maximum solubility in relation to the solvent will have been achieved. A polymer will be water-soluble in its salt form when it contains a sufficient number of acid groups. A comparatively hydrophobic material such as polymethyl methacrylate will require a much higher proportion of carboxyl groups to achieve solubility in aqueous alkali than a more hydrophilic one such as polyethylacrylate [30].

Swelling of the polymer particle is similarly dependent. Thus, a copolymer emulsion of styrene with $25 \%$ acrylic acid did not thicken at all with alkali, whereas ethyl acrylate copolymerized with only $10 \%$ acrylic acid increased in viscosity by a factor of ten [31]. Whether, or in what ratio, solubilization and swelling occur will depend on the concentration of carboxyl groups and surfactant, and the compatibility of the surfactant with the polymer in the given system [29]. The electroviscous effect [32] depends on the degree of ionization and the electric charges surrounding the particle.

Keeping in mind that the main purpose of the challenge is to create the solid thin film, which is able to regulate the flow of chemicals between the surface and its surroundings, i.e. is capable to change its permeability, the

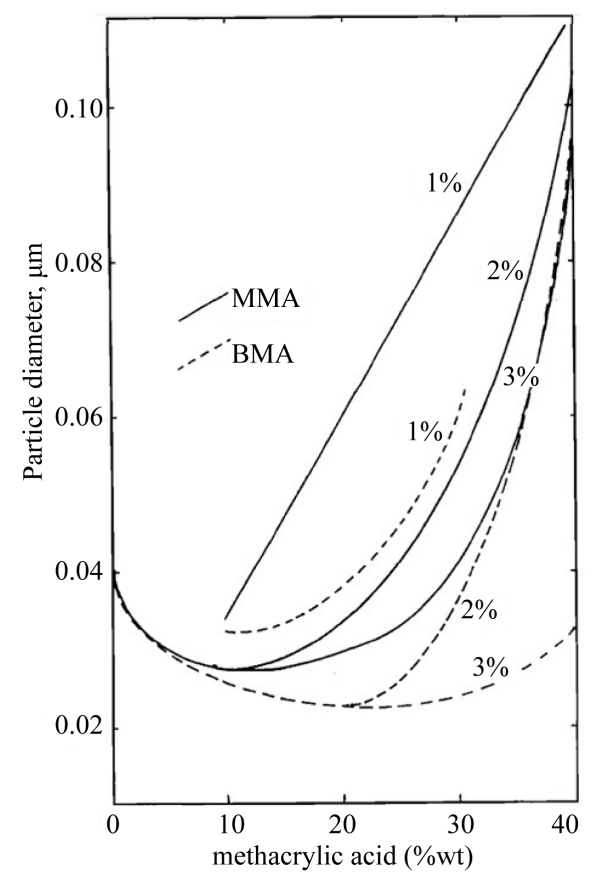

Figure 1. Variation of polymer particle diameter in emulsion with quantity of copolymerized methacrylic acid [22]: solid line-MMA, dashed lineBMA; \% figures indicate ratio of sodium dodecyl sulfate to monomer. 
most interesting results of paper [22] are related to possibility to control a water-susceptibility of copolymers of methylacrylate esters with methacrylic acid. As method for evaluation of water-susceptibility the author [22] used the measurements of the optical densities (Table 4). They were determined on the emulsion diluted to a non-volatile of $10 \%$, and adjusted to $\mathrm{pH} 8.4$ - 8.6, through a $10 \mathrm{~mm}$ glass cell using filtered light of wavelength $580 \mathrm{~nm}$. Table 3 and Table 4 show changes in optical density for three types of copolymers at different concentration of methacrylic acid.

In general, increase of the methacrylic acid and the anionic surfactant contents led to increased solubilization. Further, at a constant anionic surfactant: monomer ratio of $2 \%$, solubility decreased with the ester in the order: methyl > ethyl > n-butyl, as expected from the increasing degree of hydrophobicity of the ester.

Comparison of viscosity at high $\mathrm{pH}$ with methacrylic acid content (Figure 2) is interesting in that the minimum quantity of acid required for thickening to be achieved increased from MMA to BMA, corresponding to the order of decreasing solubility of these monomers in water. But, with $30 \%-40 \%$ methacrylic acid, the viscosity increased in the order methyl < ethyl $<$ n-butyl, i.e. as the solubility of the polymer salt in water decreased (Table 3), indicating that an important proportion of the increase in viscosity is to be attributed to swelling of the particles, as found in paper [31] for a series of acrylic ester copolymer emulsions. The group of emulsions described in paper [22] should be regarded as an example of the type and range of products which can be designed. The rheology at high $\mathrm{pH}$ can be further modified, for example, by the introduction of a minor proportion of a cross-linking agent.

The main application for $\mathrm{pH}$-sensitive polymers described in [11]-[21], and, later in [33] [34] is related to their use in cosmetic field, as well as in aqueous paints, textile coatings and oil-well drilling.

Another large field of applications for such materials is controlled release carrier systems for targeted delivery of fragrances, as well as active ingredients, onto fabric, hair, skin, and other biological surfaces that is activated by changes in $\mathrm{pH}$ or salt concentration in the system proximate environment [35], as well as drug delivery systems [36]-[41]. The pH-sensitive materials can be insoluble solids in acidic or basic aqueous solutions, which dissolve, or degrade and dissolve, as the $\mathrm{pH}$ of the solution is neutral. The $\mathrm{pH}$-sensitive materials can be insoluble solids in acidic or basic aqueous solutions which dissolve, or degrade and dissolve, as the $\mathrm{pH}$ of the solution rises above or drops below a trigger $\mathrm{pH}$ value [35].

According to patent [35], additional $\mathrm{pH}$-sensitive materials include poly functional polymers containing mul-

Table 3. Changes in optical density for copolymers MMA-MA and BMA-MA at different concentration of methacrylic acid and two different concentrations of surfactant [22]. Optical densities at pH 8.5.

\begin{tabular}{ccccc}
\hline \multirow{2}{*}{ Methacrylic acid } & \multicolumn{2}{c}{ Methyl methacrylate } & \multicolumn{2}{c}{ n-Butyl methacrylate } \\
\cline { 2 - 5 } & \multicolumn{2}{c}{ Anionic surfactant } & \multicolumn{2}{c}{ Anionic surfactant } \\
\hline & $1 \%$ & $3 \%$ & $1 \%$ & 0.52 \\
$10 \%$ & $>1.00$ & 0.59 & $>1.00$ & 0.30 \\
$20 \%$ & 0.46 & 0.10 & 0.56 & 0.25 \\
$30 \%$ & 0.04 & 0.04 & -07 & 0.07 \\
$40 \%$ & 0.01 & 0.01 & - & \\
\hline
\end{tabular}

Table 4. Changes in optical density for copolymers MMA-MA, EMA-MA and BMA-MA at different concentration of methacrylic acid [22]. Optical densities at pH 8.5 (Anionic surfactant: =2\%).

\begin{tabular}{cccc}
\hline Methacrylic acid & Methyl methacrylate & Ethyl methacrylate & n-Butyl methacrylate \\
\hline$\%$ & $>1.00$ & - & $>1.00$ \\
$10 \%$ & 0.66 & 0.20 & 0.57 \\
$20 \%$ & 0.13 & 0.05 & 0.29 \\
$30 \%$ & 0.04 & 0.03 & - \\
$40 \%$ & 0.01 & 0.07 \\
\hline
\end{tabular}




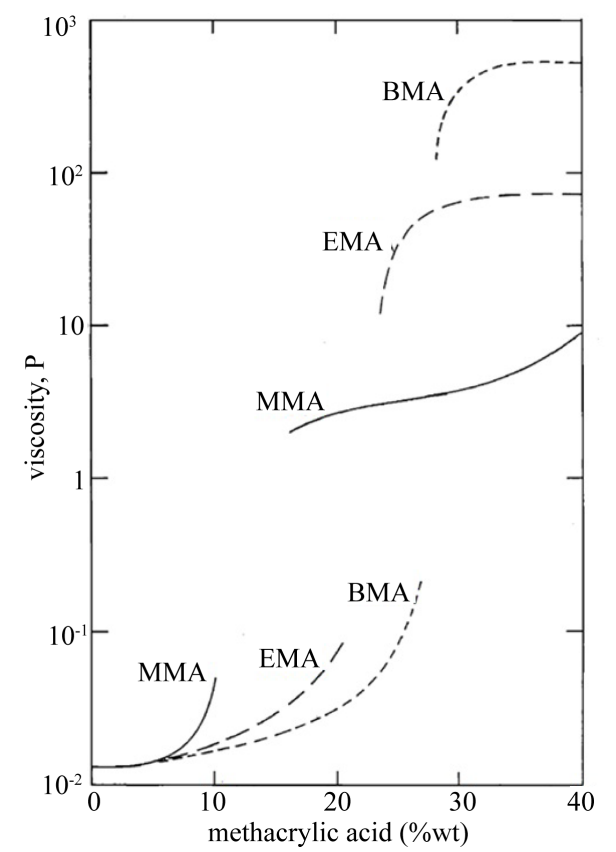

Figure 2. Variation of viscosity with quantity of copolymerized methacrylic acid [22] $(\mathrm{pH}=8.5$, content of non-volatile 10\%).

tiple groups that become ionized as the $\mathrm{pH}$ drops below their pKa. A sufficient quantity of these ionizable groups must be incorporated in the polymer such that in aqueous solutions having a $\mathrm{pH}$ below the pKa of the ionizable groups, the polymer dissolves. These ionizable groups can be incorporated into polymers as block copolymers, or can be pendent groups attached to a polymer backbone, or can be a portion of a material used to crosslink or connect polymer chains. Examples of such ionizable groups include polyphosphene, vinyl pyridine, vinyl aniline, polylysine, polyornithine, other proteins, and polymers with substituents containing amino moieties.

Besides of copolymers of methylacrylate esters with methacrylic acid other examples of $\mathrm{pH}$-sensitive materials include copolymers of acrylate polymers with amino substituents, polyacrylamides, phthalate derivatives (i.e., compounds with covalently attached phthalate moleties) such as acid phthalates of carbohydrates, amylose acetate phthalate, cellulose acetate phthalate, other cellulose ester phthalates, vinyl acetate and crotonic acid copolymers.

Examples of suitable pH sensitive polymers for use are the Eudragit ${ }^{\circledR}$ polymers series from Evonik, Inc. [36] [38]. For instance (Figure 3), Eudragit ${ }^{\circledR}$ L 30 D-55 and Eudragit ${ }^{\circledR}$ L 100-55 are pH dependent anionic polymers that are soluble at $\mathrm{pH}$ above 5.5 and insoluble below $\mathrm{pH}$. These polymers can be utilized for targeted drug delivery in the duodenum. Eudragit ${ }^{\circledR} \mathrm{L} 100$ is $\mathrm{pH}$ dependent anionic polymer that is soluble at $\mathrm{pH}$ above 6.0 for targeted drug delivery in the jejunum. Eudragit ${ }^{\circ} \mathrm{S} 100 \mathrm{is} \mathrm{pH}$ dependent anionic polymer that is soluble at $\mathrm{pH}$ above 7.0 for targeted drug delivery in the ileum [27]. Eudragit ${ }^{\circledR}$ E 100 and Eudragit ${ }^{\circledR}$ EPO, pH dependent cationic polymer, are soluble up to $\mathrm{pH} 5.0$ and insoluble above $\mathrm{pH} 5.0$ [35].

For instance, Eudragit ${ }^{\circledR}$ L 100 and Eudragit ${ }^{\circledR}$ S 100 (Figure 4) are copolymers of MMA and metacrylic acid [37] with the ratio of the free carboxyl groups to the ester groups approx. 1:1 and 1:2, respectively and molecular weight about $135 \mathrm{~K}$.

1 Commercial form EUDRAGIT ${ }^{\circledR}$ L 100 Solid substance. The product contains $0.3 \%$ Sodium Laurylsulfate Ph. Eur./NF on solid substance. EUDRAGIT ${ }^{\circledR}$ L 100 is described as Copolymer (1:1), Type A or Copolymer L in the monographs quoted above. EUDRAGIT ${ }^{\circledR}$ S 100 Solid substance. The product contains $0.3 \%$ Sodium Laurylsulfate Ph. Eur./NF on solid substance. EUDRAGIT® S 100 is described as Copolymer (1:2), Type B or Copolymer $\mathrm{S}$ in the monographs quoted above.

2 Chemical structure EUDRAGIT ${ }^{\circledR}$ L 100 and EUDRAGIT ${ }^{\circledR}$ S 100 are anionic copolymers based on methacrylic acid and methyl methacrylate. The ratio of the free carboxyl groups to the ester groups is approx. 1:1 in EUDRAGIT ${ }^{\circledR}$ L 100 and approx. 1:2 in EUDRAGIT ${ }^{\circledR}$ S 100. 


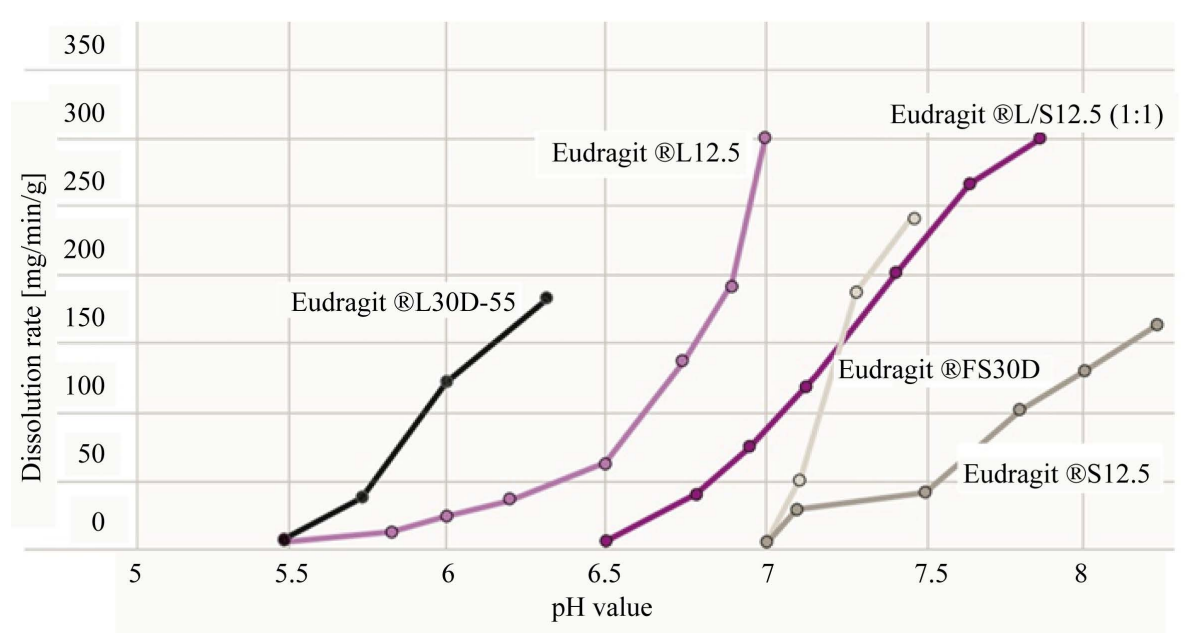

Figure 3. pH-sensitive behavior of Eudragit ${ }^{\circledR}$ L and S-polymers [38].

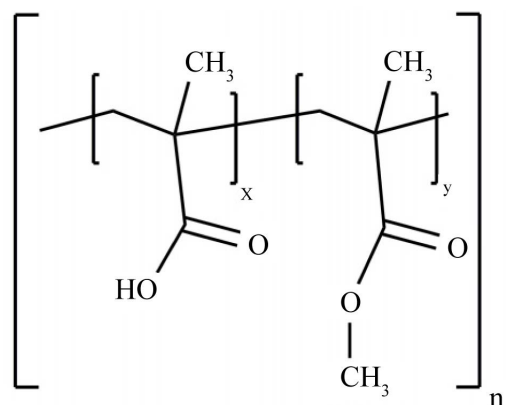

Figure 4. Chemical structure of Eudragit ${ }^{\circledR}$ L 100 and Eudragit ${ }^{\circ}$ S 100 [37].

According to [37] $1 \mathrm{~g}$ of EUDRAGIT® L 100 or EUDRAGIT® S 100 dissolves in $7 \mathrm{~g}$ methanol, ethanol, in aqueous isopropyl alcohol and acetone (containing approx. 3\% water), as well as in $1 \mathrm{~N}$ sodium hydroxide to give clear to slightly cloudy solutions. EUDRAGIT® L 100 and EUDRAGIT® S 100 are practically insoluble in ethyl acetate, methylene chloride, petroleum ether and water.

EUDRAGIT $^{\circledR}$ polymers are available as granules, powders, aqueous dispersions and organic solutions (Table 5) [38] [42].

Due to the variation in physical state, the polymers can be applied using every common processing technology from direct compression to high-shear granulation, as well as innovative technologies like melt extrusion [36]. In wet granulation processes the polymers can be used as granulating binders in both organic and aqueous processing. EUDRAGIT ${ }^{\circledR}$ NE 40 D, an aqueous dispersion with $40 \%$ polymer content, has been launched to accommodate situations where a reduced amount of granulating fluid is desired. The powder grades can be utilized in granulation processes to offer the advantages of increased polymer content and a shortened process time. The higher the distribution of the matrix former, the stronger will be the SR effect in the tablet. Strongest retardation is achieved by processing organic polymer solutions or by melt techniques where the polymer distribution is molecular. Plasticizers may even improve the retardation effectiveness. As in film coating, EUDRAGIT ${ }^{\circledR}$ poly- $^{-}$ mers can be combined with each other for matrix applications. This flexibility offers the possibility to create desired release patterns by using various polymer functionalities [36].

In summary, taking into consideration that the specialists who are taking care about the wood protection most likely are looking for the method of applying the coating onto the surface through spraying or dipping and they would prefer that the coating formula are aqueous based, it is possible to conclude that the $30 \%$ aqueous dispersion of EUDRAGIT ${ }^{\circledR}$ polymers, such as L30D-55 and FS30D, available from Evonik, Inc. [38] are the strong candidate for the coating with desirable qualities. 
Table 5. Availability and dissolution properties of EUDRAGIT ${ }^{\circledR}$ polymers [38].

\begin{tabular}{ccc}
\hline EUDRAGIT ${ }^{\circledR}$ Polymers & Availability & Dissolution properties \\
\hline L 30D-55 & 30\% Aqueous Dispersion & Dissolution above $\mathrm{pH} 5.5$ \\
L 100-55 & Powder & Dissolution above $\mathrm{pH} 5.5$ \\
L 100 & Powder & Dissolution above $\mathrm{pH} 6.0$ \\
L 12.5 & $12.5 \%$ Organic Solution & Dissolution above pH 6.0 \\
S 100 & Powder & \\
S 12.5 & $12.5 \%$ Organic Solution & Dissolution above $\mathrm{pH} 7.0$ \\
FS $30 \mathrm{D}$ & $30 \%$ Aqueous Dispersion & Dissolution above $\mathrm{pH} 7.0$ \\
\hline
\end{tabular}

\section{Regulation of the Flow of Chemicals between the Surface and Its Surroundings with Polymer Multi-Layer Structures}

\subsection{Basics of Layer-by-Layer Polymer Self-Assembly}

Hydrogen bonding is the key in determining the secondary structure of biological molecules such as proteins, nucleic acids, and the behavior of lipid membranes [43]. The power of hydrogen-bonding self-assembly has also been explored for synthetic molecules to produce three-dimensional self-assembled supramolecular polymeric structures from shorter building blocks [44]-[46]. The properties of such self-assembled materials respond strongly to environmental stimuli such as $\mathrm{pH}$, temperature, or solvent. Another type of hydrogen-bonded selfassembly is polymer-polymer self-assembly, or hydrogen bonded complexes. In such structures, two initially soluble polymers are bound within a complex through multiple hydrogen bonds along the polymer backbone, and an insoluble product is formed when the molar ratio of monomeric units is not very different from unity. Hydrogen bonded polymer complexes in aqueous solutions have been studied for several decades [47]-[50] but deposition of such complexes at surface through simple precipitation results in poor control of film quality and thickness.

A highly controlled deposition of polymers at surfaces occurs through surface directed layer-by-layer (LbL) self-assembly, first described by Decher [51] [52]. The procedure consists of alternating exposure of surfaces to solutions of polymers which are able to form polymer complexes when mixed in solution. A monolayer adsorption of a polymer is achieved at each deposition step, and the total film thickness increases with the number of deposition cycles. This process produces nanoscopically structured polymer films, with well-controlled morphology and thickness. Advantages of this technique result from the versatility of interpolymer interactions and the self-limiting nature of the amount of polymer deposited. Figure 5 contrasts the interaction of polymer chains in solution and at surfaces.

A wide range of functional molecules can be incorporated within the film, including electroactive polymers, organic dyes, semiconductor quantum dots, electrochemically active species, inorganic nanomaterials, and biologically active molecules [53]. Importantly, using the LbL technique, functional coatings can easily be created on substrates of virtually any chemistry and shape. Though non-electrostatic forces, such as hydrophobic ones, have been recognized as a significant contribution to film growth [54] [55] the LbL technique has been most widely applied to charged molecules, whose deposition at the surface is largely controlled by charge compensation mechanisms [53].

It has been demonstrated [56] that LbL film deposition in an aqueous solution can be driven primarily by hydrogen bonding interactions. Those authors showed that polyaniline can be co-self-assembled with a number of nonionic polymers such as poly(vinylpyrrolidone) (PVPON), poly(vinyl alcohol) (PVA), poly(acrylamide) (PAAM) and poly(ethylene oxide) (PEO). In this example self-assembly of neutral polymers occurred in a wide $\mathrm{pH}$ range, but polyaniline was allowed to adsorb from acidic solutions where this polymer was soluble. Multilayers were also constructed from a conjugated copolymer of the poly(phenylenevinylene) type containing hydroxyl groups which were capable of hydrogen bonding with amine groups of a co-self-assembled poly (ethyleneimine) [57].

Simultaneously with these first demonstrations of hydrogen-bonded LbL self-assembly in an aqueous envi- 

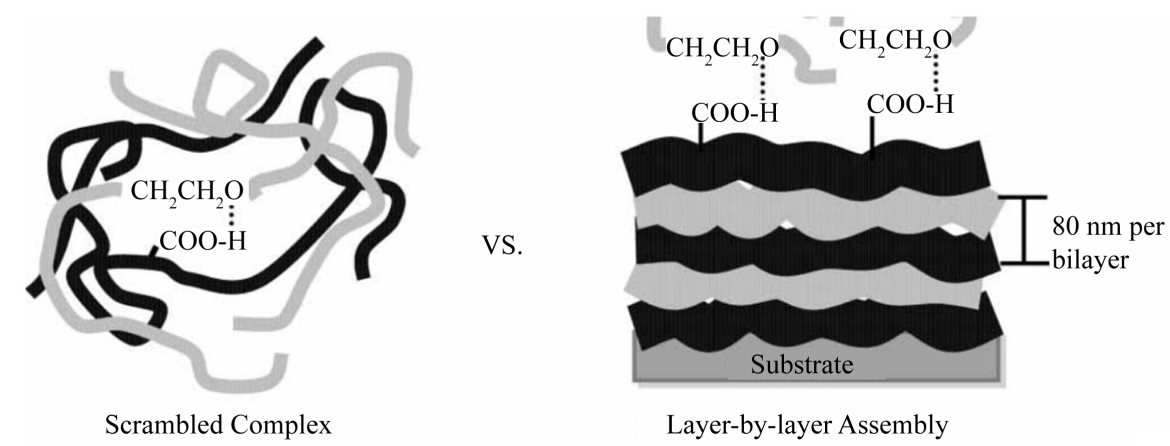

Figure 5. Solution-based complexes (left) versus LbL films (right). In contrast with scrambled complexes in solution, the LbL film exhibits nanoscale control while conformally coating the assembly substrate [43].

ronment, the use of an organic solvent or combinations of an organic solvent and water for construction of hydrogen-bonded films was explored [58]-[61]. When a combination of poly(vinylpyridine) (PVP) with poly(acrylic acid) (PAA) [62] [63] or PVP with carboxylated dendrimers [64] were self-assembled in this way, microporosity could be introduced within the film by exposing the film to an aqueous solution at basic $\mathrm{pH}$ where PAA or dendrimer components selectively dissolved. The use of organic solvents for multilayer formation widens the range of polymers to water-insoluble and nonionic polymers which can be incorporated in the multilayers.

In most recent review on the topic, the authors [43] have focused on hydrogen-bonded films produced by LbL self-assembly of a neutral polymer and a weak polyelectrolyte in an aqueous solution. The use of weak polyelectrolytes allows control of film properties by variations of $\mathrm{pH}$ during film self-assembly, as well as manipulation of film stability after construction. This approach involving self-assembly of water soluble weak polyelectrolytes, such as polycarboxylic acids and neutral polymers leads to the construction of films which are easily erasable by a $\mathrm{pH}$ increase [65] [66]. The ability of hydrogen-bonded films to absorb large amounts of functional molecules such as dyes or drugs, combined with film disintegration at neutral $\mathrm{pH}$ values suggests future applications of such systems in drug delivery. Crosslinking of hydrogen-bonded films provides film stability at physiologic $\mathrm{pH}$ and makes them attractive candidates for biomedical applications.

\section{2. pH Response of Layer-by-Layer Polymer Self-Assembly}

A unique feature of hydrogen-bonded self-assembly involving polycarboxylic acids to controllably dissolve at a higher $\mathrm{pH}$ value was first illustrated in papers [65] [66].

The critical $\mathrm{pH}$ of film disintegration was shown to be controlled by the strength of hydrogen bonding interactions within the film. In contrast to electrostatically bound films, hydrogen-bonding interactions stabilize the protonated form of the polyacid and significantly suppress polyacid ionization within the multilayer as compared to polyacid ionization in solution [66].

When $\mathrm{pH}$-induced ionization of the polyacid exceeds a critical value, film dissolution occurs. Experimental proof of the last statement has been obtained for 7 films prepared from dual combinations of polymers with a chemical structure presented in Figure 6.

Figure 7 shows the pH-triggered disintegration of hydrogen-bonding multilayers composed of PMAA and a range of neutral hydrogen-bonding polymers. Note that all polymers used in self-assembly were of similar molecular weight, except for PVCL, whose molecular weight was very low. Interestingly, in spite of the lowest molecular weight of the polymer used in film deposition, PMAA/PVCL films showed the widest interval of stability in the $\mathrm{pH}$ scale. According to data [43], an enhanced $\mathrm{pH}$ stability of PMAA/PVCL multilayers compared to PMAA/PVPON systems correlates with the presence of two extra methyl groups in the caprolactam ring and points to a stronger contribution of hydrophobic interactions to film stabilization. An additional hydrophobic contribution to stabilization of hydrogen bonded self-assembly is even more evident from the comparison of the pH-stability of the PMAA/PVME films with the PMAA/PEO system.

Specifically, more hydrocarbon moieties in the PVME chains resulted in a shift of critical $\mathrm{pH}$ by about 1.6 compared to PMAA/PEO whose dissociation occurred at $\mathrm{pH}$ 4.6. 
<smiles>CC(C)C(C)(C)C(=O)O</smiles>
(PEO)

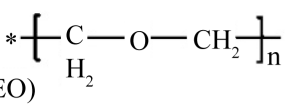<smiles>CC(C)C(N1CCCC1=O)C(C)(C)C</smiles>

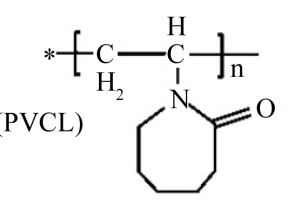<smiles>CC(C)CC(C(N)=O)C(C)C</smiles><smiles>CC(C)(C)C(C(=O)OCO)C(C)(C)C</smiles>

Figure 6. Chemical structures of polymers involved in self-assembly [43].

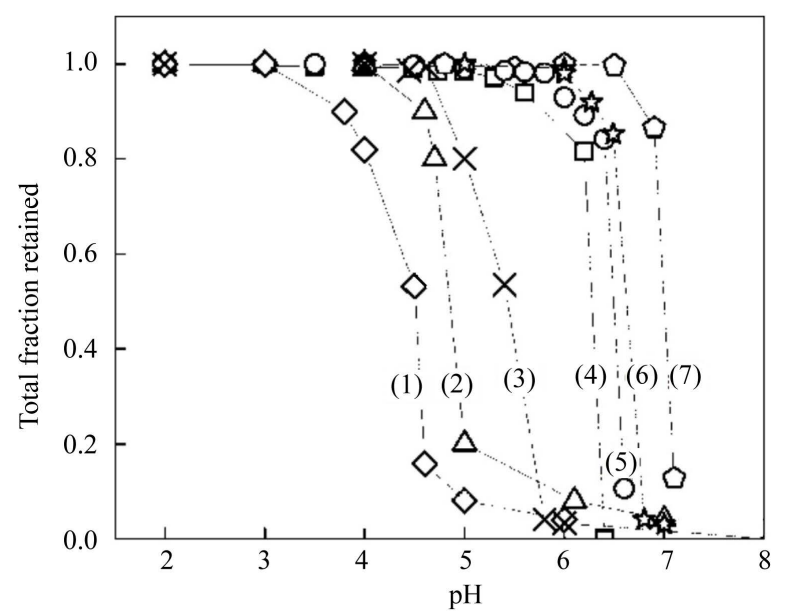

Figure 7. pH-triggered disintegration of hydrogen-bonded systems presented in Table 6: PMAA/PHEA (diamonds, curve 1), PMAA/PEO (triangles, curve 2), PMAA/PAAM (crosses, curve 3), PMAA/PVME (squares, curve 4), PMAA/PNIPAM (circles, curve 5), PMAA/PVPON (stars, curve 6), PMAA/PVCL (pentagons, curve 7). 10-layer films were deposited from $\mathrm{D}_{2} \mathrm{O}$ solutions at $\mathrm{pH} 2$ and $23^{\circ} \mathrm{C}$. The disintegration was monitored by in situ ATR-FTIR [43].

Table 6 shows that the $\mathrm{pH}$ stability of films improved as intrinsic strength of hydrogen bonding and/or hydrophobicity of the film components was increased. Correspondingly, critical $\mathrm{pH}$ for film disintegration was consistently higher for stronger bound systems.

Disadvantage of all seven polymer systems presented in Table 6 in terms of their practical application for purposes of this challenge is that their films are stable to the aqueous media only in very acidic conditions. In order to change their solubility in aqueous solutions the $\mathrm{pH}$ of solutions should be changed from highly acidic to slightly acidic or neutral.

More promising, in our opinion, is an approach based on using polyelectrolyte multilayers prepared by the layer-by-layer sequential self-assembly of a weak polybase and polyacid.

The LbL adsorption of oppositely-charged polyelectrolytes on surfaces has emerged as a simple, versatile, and inexpensive technique for the fabrication of thin multi-layer films, often with nanometer-scale control over the spatial distribution of ionized species within a film [52] [67] [68]. The LBL approach is based on electrostatic attractions between polyelectrolytes and oppositely charged surfaces. In the example shown in Figure 8, a negatively charged substrate is first dipped in a polycation solution. Electrostatic attractions result in deposition of the polycation and a resulting reversal of surface charge (see Figure 8, step 1). The positively charged substrate is then submerged in a polyanion solution, resulting in deposition of the polyanion and restoration of the 
Table 6. Critical dissolution $\mathrm{pH}$ and critical ionization for H-bonded polymer systems presented in Figure 7. The critical $\mathrm{pH}$ values were defined as the maximum values at which less than $10 \%$ of film dissolved for one hour. The critical ionization is PMMA ionization at the critical $\mathrm{pH}$ [43].

\begin{tabular}{ccc}
\hline Polymer system & Critical dissolution $\mathrm{pH}$ & Critical ionization \\
\hline PMAA/PHEA & 4.0 & $1 \%$ \\
PMAA/PEO & 4.6 & $1 \%$ \\
PMAA/PAAM & 5.0 & $4 \%$ \\
PMAA/PVME & 6.0 & $2 \%$ \\
PMAA/PNIPAAM & 6.2 & $3 \%$ \\
PMAA/PVPON & 6.4 & $\sim 8-10 \%$ \\
PMAA/PVCL & 6.95 & $30 \%$ \\
\hline
\end{tabular}

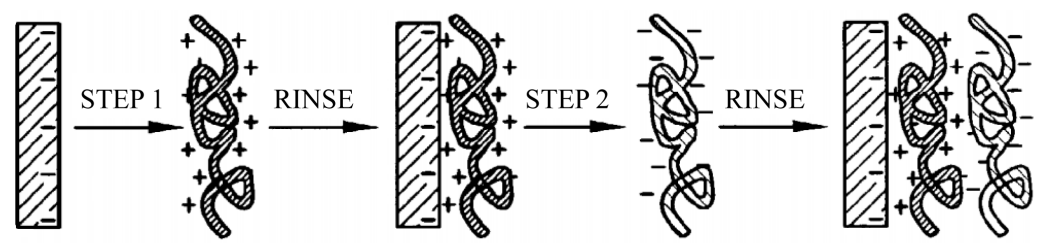

Figure 8. Schematic illustrating the construction of a thin film via layer-by-layer deposition of polyelectrolytes on a charged substrate [68].

negative charge on the surface (see Figure 8, step 2).

Repetition of these steps leads to the buildup of layers of alternating oppositely charged polyelectrolytes on the substrate surface. In addition to electrostatics, other factors and secondary interactions such as hydrophobicity, salt interactions, solvent quality, polymer concentrations, and deposition time may affect the multi-layer growth of the film [68].

Patent [68] described the construction and decomposition of a thin film by LbL-method, as presented in Figure 9, where the stage $\mathrm{A}$ is a LbL-deposition of alternating polyanionic and polycationic layers and stage $\mathrm{B}$ is a degradation of polycationic layers and release of polyanionic components, which is possible, by changing $\mathrm{pH}$ of surrounding media. As an example of $\mathrm{pH}$-sensitive behavior of the LbL-films paper [69] described the formation of polyelectrolyte multilayers from the partially quaternized poly-4-vinylpyridine (degree of quaternization from 12 to 98\%) as polybases (generally abbreviated as QPVP) and poly(methacrylic acid) (PMAA) as a polyacid. The adsorption and ionization of pyridine rings and carboxylic groups were quantified using Fourier transform infrared spectroscopy in attenuated total reflection mode (Figure 10).

It was found that in slightly acidic conditions at $\mathrm{pH}=5$, film growth was primarily controlled by electrostatic interactions. When QPVP was included into the top layer, ionization of carboxylic groups was increased compared to its value in solution. The amount of the induced charge increased linearly with the total charge density of the polybase (calculated as a sum of ethylated pyridinium and protonated pyridinium groups), suggesting the formation of both types of electrostatic pairs $\left(\mathrm{COO}^{-}-\mathrm{NR}^{+}\right.$and $\left.\mathrm{COO}^{-}-\mathrm{NH}^{+}\right)$[69]. The degree of ionization of both pyridine groups and carboxylic groups within the film responded to the charge of the polymer included in the top layer and oscillated as a function of layer number. The average ionization of the carboxylic groups within the multilayer was suppressed when the multilayer was topped with PMAA, and it was enhanced when the top layer was the polybase.

When the $\mathrm{pH}$ of the buffer solution was lowered below $\mathrm{pH}=2$, multilayers dissolved due to protonation of carboxylic groups and disruption of polymer/polymer ionic contacts. The multilayer stability under acidic conditions was dependent on the alkylation degree of QPVP. With the exception of the largest alkylation degrees, the stability of the film increased with the alkylation degree of QPVP. The multilayer destruction correlated with the protonation of the small $(<5 \%)$ residual fraction of carboxylic groups that was included into polymer/polymer ionic pairs and with the number of ionic polymer/polymer contacts per QPVP chain, suggesting that the number of polymer/polymer contacts during self-assembly was a critical parameter in multilayer stability. The results 


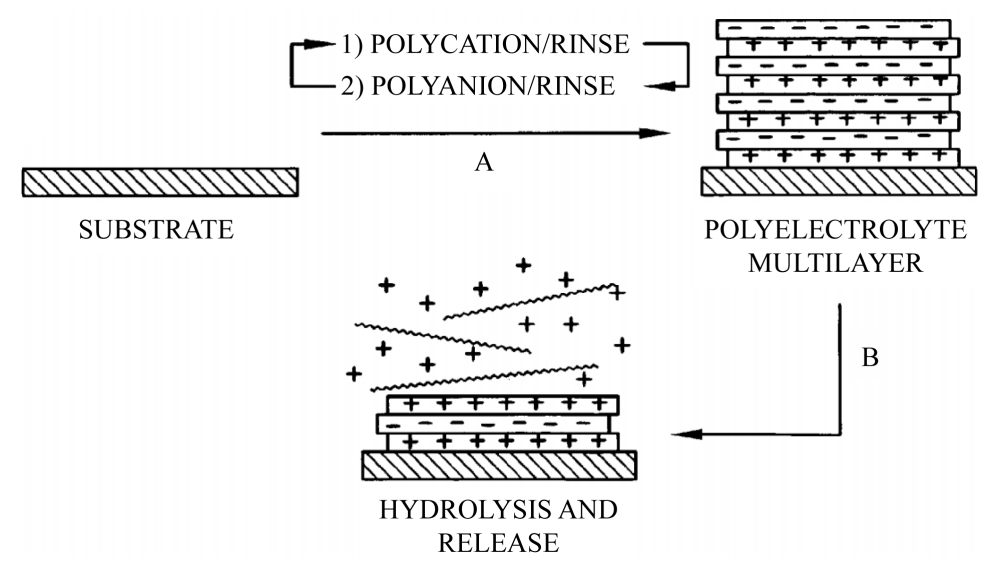

Figure 9. Schematic illustrating the construction and decomposition of a thin film: (A) layer-by-layer deposition of alternating polyanionic and polycationic layers and (B) degradation of polycationic layers and release of polyanionic components [68].

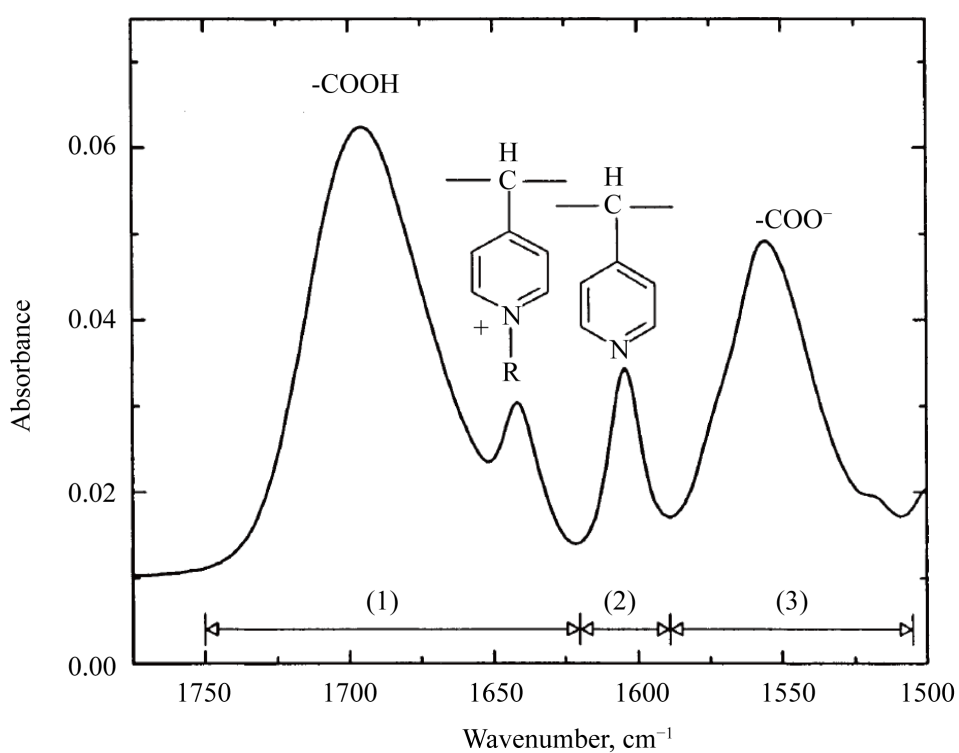

Figure 10. Representative FTIR-ATR spectrum of 10 layers of PMAA and QPVP with degree of quaternization 20\% (Quaternization was performed with using ethyl bromide) [60].

show the effect of the QPVP charge density on the ionization of self-assembled PMAA and on the pH stability of polyelectrolyte multilayers.

As the $\mathrm{pH}$ was lowered, carboxylic groups of PMAA deprotonated and pyridine groups of QPVP protonated, which resulted in an increase of the ratio of positive to negative charges within the film. In was found [69] that the multilayer was stable up to $\mathrm{pH}=2$, but dissolved when the $\mathrm{pH}$ was decreased below this point. The transition was narrow, less than 0.2 units of $\mathrm{pH}$; that proved the cooperative nature of the response. The authors [69] observed that the multilayer stability at acidic conditions was dependent on the alkylation degree of the composing QPVP molecules. Figure 11 shows the fraction of the multilayer remaining on the surface after 40 min of exposure of the multilayer to a buffer solution, plotted as a function of $\mathrm{pH}$ for various degrees of alkylation of QPVP.

As for stability of PMAA/QPVP at higher pH, PMAA/Q37 and PMAA/Q98 films assembled at pH 5 become solubilized when exposed to $\mathrm{pH}$ 7. On the other hang PMAA/Q20, if sufficiently thin, can tolerate this $\mathrm{pH}$ change, but they selectively release PMAA. It was found that the first PMAA layer closes to the substrate, does not release its PMMA due to "pinning" of polymer chains to a solid surface. The amount of polymers deposited 


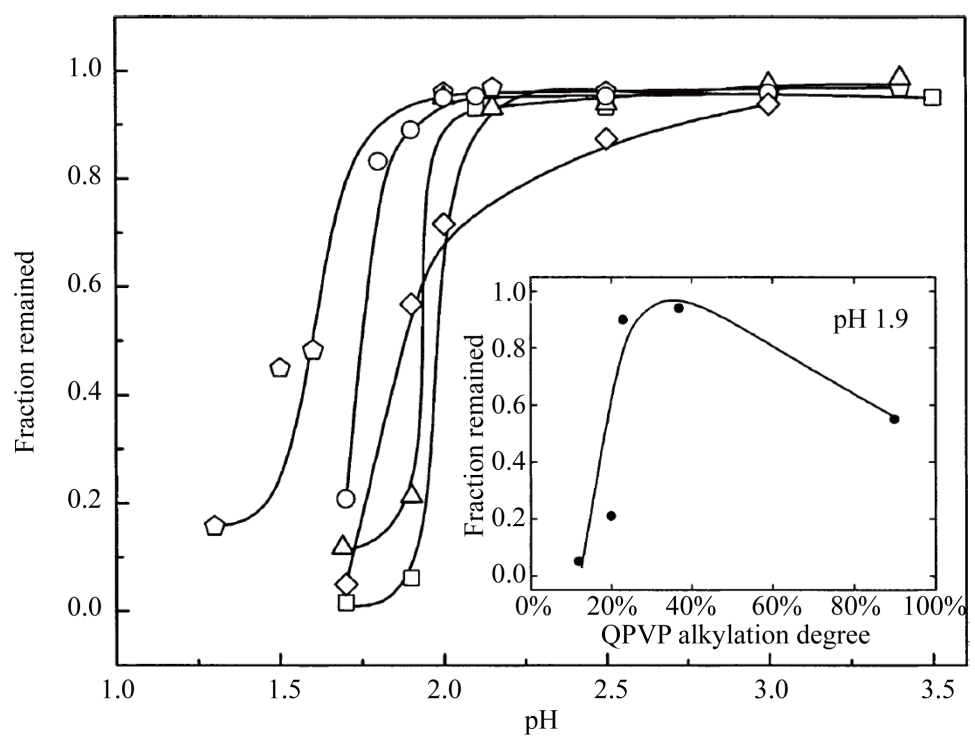

Figure 11. Comparison of pH-triggered disintegration of multilayers in the PMAA/ Q12 (squares), PMAA/Q20 (triangles), PMAA/Q25 (circles), PMAA/Q37 (pentagons), and PMAA/Q90 (diamonds) systems. The relative mass adsorbed after 40 min is plotted as a function of $\mathrm{pH}$. The inset shows the relative mass remaining at the surface after 40 min of disintegration of multilayers as a function of the alkylation degree of QPVP at a fixed $\mathrm{pH}$ of 1.9 [69].

within the first 2-3 polymer bilayers has been shown to differ from that deposited within the "bulk" of the film. Moreover, it was demonstrated [70] that the proximity of the substrate also significantly suppresses the pHtriggered release of polymer chains (Figure 12).

The biggest disadvantage of the LbL method is its complexity and low rate of the film deposition. The layerby-layer self-assembling process in its initial stage requires special attention. The mechanical and temporal stability of the first molecular layers tethered to a solid substrate is a critical element to the homogeneity of thicker films. The concentration of interlayer defects depends to a great extent upon the homogeneity, affinity, and microroughness of this first monolayer. A gradient of molecular ordering across the first several (usually 3 - 5) molecular layers is observed for various molecular films [71]-[73]. This phenomenon is usually related to healing of substrate inhomogeneities and nonequilibrium behavior [74]. Formation of nonequilibrium surface morphologies and inhomogeneous coverage is caused by the competition of the kinetics of polymer chain adsorption and their surface diffusion. According to [73] [74], kinetic limitations are imposed on the formation of organized multilayers from polyonic materials. In fact, stable and consistent layer-by-layer growth of self-assembled films is observed only after a certain deposition time. It is suggested that assembly of polyions on charged surfaces is indeed a two-stage process: macromolecular chains are anchored to the surface by some segments during the short initial stage and then relax to a dense packing during the long stage of self-assembly [74]. Presumably, a stable homoheneous polymer monolayer which covers the original surface is formed only after complete "relaxation" of adsorbed macromolecules.

Papers [69] [70] provide the following description of the multilayers' deposition. Briefly, the substrate was first primed with a quaternized PVP (Q20), which adsorbed at the amount approximately $1.5 \mathrm{mg} / \mathrm{m}^{2}$. Then 0.1 $\mathrm{mg} / \mathrm{mL}$ solution of PMAA was allowed to adsorb onto the surface of the substrate at $\mathrm{pH} 5$ from $0.01 \mathrm{M}$ phosphate buffer solution for $20 \mathrm{~min}$, and after that polymer solution was replaced by the buffer without polymer. QPVP was then deposited in a similar way, and the deposition cycle was repeated. In general, a growth of PMAA/QPVP films is linear, with individual layer coverages of $1.7 \mathrm{mg} / \mathrm{m}^{2}$ and $3.3 \mathrm{mg} / \mathrm{m}^{2}$ and thicknesses of 1.7 and $3.3 \mathrm{~nm}$ (for density of $1 \mathrm{~g} / \mathrm{cm}^{3}$ ) for PMAA and QPVP, respectively [70].

\section{Conclusions}

In summary, the authors analyzed the positive features, as well as some drawbacks of three major types of pro- 


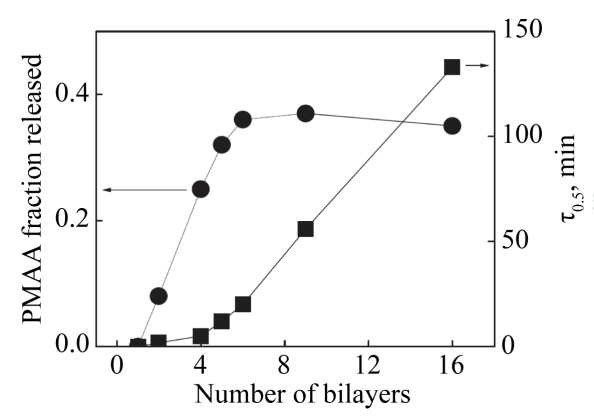

Figure 12. Polyacid fraction released (circles, left axis) and characteristic half-time (squares, right axis) for PMMA release from PMAA/ Q20 films of different thicknesses (films are exposed to buffer solution at $\mathrm{pH}=7[70]$.

tective coating of wood and wood-based materials which include the coatings based on carboxyl-containing water-soluble polymers which are easily cross-linked by inorganic salts or $\mathrm{OH}$-containing compounds, $\mathrm{pH}$-sensitive coatings and polymer multi-layer structures.

Considering the first of three mentioned approaches, the authors are emphasizing that the crosslinking PAA films with metal cations, as well as crosslinking reactions between the proton-donating pendent -COOH groups in PAA molecules and polar $\mathrm{OH}$ groups of glycerol, other polyhydric alcohols or gelatin, for example, should be considered as one of the promising methods to affect permeability and enhance the prevention the loss of water from the surface of wood to its surrounding. The strong specific feature of the second approach is related to the possibility to vary and purposely adjust the polymer composition and the number and distribution of -COOH groups in the chain which make the originally water-soluble polymers completely insoluble. The unique advantage of emulsions of such polymers is that being thick enable in situ, and can thus be stored and handled as low viscosity fluids until such time as their thickening property is to be utilized. Finely, the third approach which is still not utilized in practice offers the possibility of manipulation of film stability after construction due to the broad use of hydrogen-bonded films produced by LbL self-assembly of a neutral polymer and a weak polyelectrolyte in an aqueous solution.

\section{References}

[1] Bulian, F. and Graystone, J. (2009) Wood Coatings Theory and Practice. Elsevier Science, Amsterdam. http://public.eblib.com/choice/publicfullrecord.aspx?p=452866

[2] Thompson, R. (1991) The Chemistry of Wood Preservation (Google eBook) Elsevier, 1 Jan 1991, Technology \& Engineering, $316 \mathrm{p}$.

[3] Niska, K.O. and Sain, M. (2008) Wood-Polymer Composites. CRC Press, Cambridge, England City; Boca Raton, Fla, 368 p. http://dx.doi.org/10.1533/9781845694579

[4] Kennedy, J.F., Phillips, G.O. and Williams, P.A. (1996) The Chemistry and Processing of Wood and Plant Fibrous Material: Cellucon '94 Proceedings (Google eBook) Elsevier, 1 Jan 1996, Technology \& Engineering, 448 p.

[5] http://www.panna.org/resources/caia/corpProfilesDow

[6] Sustainable Paint: Eco Friendly Interior Design. http://www.intelligentinteriors.net/sustainable-paint-eco-friendly-interior-design/

[7] Żak, S., Rauckyte-Żak, T., Laurinavičius, A. and Siudziński, P. (2014) Research on Physico-Chemical Pretreatment of Wastewater from the Production of Wood Coating materials. Ecological Chemistry and Engineering S, 21, 101-112. http://dx.doi.org/10.2478/eces-2014-0009

[8] Jewell, L.L., Fasemore, O.A., Glasser, D., Hildebrandt, D., Heron, L., Van Wyk, N., et al. (2004) Toward Zero Waste Production in the Paint Industry. Water SA, 30, 643-647. http://dx.doi.org/10.4314/wsa.v30i5.5175

[9] Grāvitis, J., Ābolinš, J., Tupčiauskas, R. and Vēveris, A. (2010) Lignin from Steam-Exploded Wood as Binder in Wood Composites. Journal of Environmental Engineering and Landscape Management, 18, 75-84. http://dx.doi.org/10.3846/jeelm.2010.09

[10] Bellotti, N., Deyá, C., del Amo, B. and Romagnoli, R. (2012) “Quebracho” Tannin Derivative and Boosters Biocides for New Antifouling Formulations. Journal of Coatings Technology and Research, 9, 551-559. 
http://dx.doi.org/10.1007/s11998-012-9403-0

[11] Grynkiewicz-Bylina, B. (2011) Testing of Toxic Elements Migration from the Materials Used as Toy Coatings. Ecological Chemistry and Engineering. S, 18, 223-231.

[12] Gregor, H.P., Luttinger, L.B. and Loebl, E.M. (1955) Metal-Polyelectrolyte Complexes. I. The Polyacrylic AcidCopper Complex. The Journal of Physical Chemistry, 59, 34-39. http://dx.doi.org/10.1021/j150523a011

[13] Luttinger, L. and Cassidy, H.G. (1956) Electron Exchange Polymers. VIII. The Redox Potentials of Polymeric Hydroquinones. Journal of Polymer Science, 22, 271-290.

[14] Gregor, H.P., Luttinger, L.B. and Loebl, E.M. (1955) Metal-Polyelectrolyte Complexes. II. Complexes of Copper with Cross-linked Polyacrylic and Polymethacrylic Acids. The Journal of Physical Chemistry, 59, 366-368. http://dx.doi.org/10.1021/j150526a020

[15] Habert, A.C., Huang, R.Y.M. and Burns, Ch.M. (1979) Ionically Crosslinked Poly(Acrylic Acid) Membranes. I. Wet Technique. Journal of Applied Polymer Science, 24, 489-501. http://dx.doi.org/10.1002/app.1979.070240216

[16] Winkleman, A., McCarty, L.S., Zhu, T., Weibel, D.B., Suo, Z., Whitesides, M., Rodriguez, L.N.J. and Whitesides, G.M. (2007) Patterning Micron-Sized Features in a Cross-Linked Poly(acrylic acid) Film by a Wet Etching Process. Soft Matter, 3, 108-116. http://dx.doi.org/10.1039/B611630B

[17] Lars-åke, L. and Rabek, J.F. (1993) Structures and Mechanisms of Formation of Poly(acrylic acid)-Iron (II and III) Chloride Gels in Water and Hydrogen Peroxide. Journal of Applied Polymer Science, 50, 1331-1341. http://dx.doi.org/10.1002/app.1993.070500804

[18] ROHM and HAAS Technical Note "Polyacrylic Acid Homopolymer". http://www.dow.com/assets/attachments/business/pmat/acumer/acumer_1510/tds/acumer_1510.pdf

[19] Report on the EPA Grant Number: R829621. Membrane-Based Nanostructured Metals for Reductive Degradation of Hazardous Organics at Room Temperature. 2002. http://cfpub.epa.gov/ncer_abstracts/index.cfm/fuseaction/display.abstractDetail/abstract/2172/report/2002

[20] Tang, Q., Wu, J., Lin, J., Fan, S. and Hu, D. (2009) A Multifunctional Poly(acrylic acid)/Gelatin Hydrogel. Journal of Materials Research, 24, 1653-1661. http://dx.doi.org/10.1557/jmr.2009.0210

[21] Sugama, T., Kukacka, L.E. and Cardiello, N. (1984) Nature of Interfacial Interaction Mechanisms between Polyacrylic Acid Macromolecules and Oxide Metal Surfaces. Journal of Materials Science, 19, 4045-4056.

[22] Gulbekian, E.V. (1970) A Group of Alkali-Thickenable Methacrylate Copolymer Emulsions. Journal of the Society of Cosmetic Chemists, 21, 471-482.

[23] Wilson, W.K. (1953) Copolymers and Copolymer Emulsions of Salts of Monoalkyl Esters of Maleic Acid. US Patent No. 2643245.

[24] Starck, W., Taunus, H. and Billig, K. (1941) Interpolymerization Product of Vinyl Acetate and Crotonic Acid. US Patent No. 2263598.

[25] Leamington, S. (1959) Improvements in or Relating to Polymers with Organic Solvent and Water Solubility. British Patent No. 856403.

[26] Davies, R.F.B. and Reynolds, G.E.J. (1968) Alkaline Hydrolysis of Aqueous Polymer Dispersions, Particularly Vinyl Acetate Copolymers. Journal of Applied Polymer Science, 12, 47-58. http://dx.doi.org/10.1002/app.1968.070120106

[27] King, A.P. and Naidus, H. (1969) The Relationship between Emulsion Freeze-Thaw Stability and Polymer Glass Transition Temperature. I. A Study of the Polymers and Copolymers of Methyl Methacrylate and Ethyl Acrylate. Journal of Polymer Science Part C: Polymer Symposia, 27, 311-319. http://dx.doi.org/10.1002/polc.5070270122

[28] Issacs, P.K. and Edelhauser, H.A. (1966) Influence of Polymer Solubilization on Latex Behavior. Journal of Applied Polymer Science, 10, 171-183. http://dx.doi.org/10.1002/app.1966.070100113

[29] Gulbekian, E.V. and Sweetingham, M.J. (1968) Proceedings of the 5th International Congress of Surface Activity, Barcelona, 9, 965.

[30] Muroi, S., Hosoi, K. and Ishikawa, T. (1967) Alkali Solubility of Carboxylated Polymer Emulsions. Journal of Applied Polymer Science, 11, 1963-1978. http://dx.doi.org/10.1002/app.1967.070111013

[31] Wesslau, H. (1963) Zur kenntnis von acrylsäure enthaltenden copolymerdispersionen. II. Die verdickbarkeit arcrylsäure enthaltender dispersionen. Die Makromolekulare Chemie, 69, 220-240. http://dx.doi.org/10.1002/macp.1963.020690118

[32] Stone-Masui, J. and Watillon, A. (1975) Characterization of Surface Charge on Polystyrene Lattices. Journal of Colloid and Interface Science, 52, 479-503. http://dx.doi.org/10.1016/0021-9797(75)90273-8

[33] Siegert, W. (1990) Production Hygiene in Manufacture of Water-Based Coating Materials. Polymers, Paint and Colour Journal, 180, 584-585. 
[34] Kuropka, R. (1998) Copolymers Containing Carboxyl Groups in Aqueous Dispersion Form or Redispersible Powder Form and Their Water-Soluble Salts, Processes for Their Preparation and Their Use as Thickeners in Aqueous Formulations. US Patent No. 5705553.

[35] Shefer, A., et al. (2003) Targeted Controlled Delivery Compositions Activated by Changes in pH or Salt Concentration. US Patent Application, 20030195133.

[36] http://eudragit.evonik.com/product/eudragit/en/application-and-technologies/matrix-formulations/Pages/default.aspx

[37] http://eudragit.evonik.com/sites/dc/Downloadcenter/Evonik/Product/EUDRAGIT/Specification\%20EUDRAGIT®\%20 L\%20100_S\%20100.pdf http://eudragit.evonik.com/product/eudragit/Documents/evonik-specification-eudragit-l-100-and-eudragit-s-100.pdf

[38] http://eudragit.evonik.com/sites/dc/Downloadcenter/Evonik/Product/EUDRAGIT/EUDRAGIT®\%20Products.pdf http://eudragit.evonik.com/product/eudragit/Documents/evonik-brochure-eudragit.pdf

[39] Hoffman, A.S., et al. (1995) Block and Graft Copolymers and Methods Relating Thereto. Intern. Patent No. WO 95/24430.

[40] Bae, Y.H., et al. (2010) pH-Sensitive Polymeric Micelles for Drug Delivery. US Patent No. 7659314.

[41] Brown, L.R. (2008) Production of Microspheres. US Patent No. 7374782.

[42] Papola, V., Rajan, G. and Bisht, S. (2013) Eudragit and Chitosan—The Two Most Promising Polymers for Colon Drug Dilevery. International Journal of Pharmaceutical \& Biological Archives, 4, 399-410.

[43] Kharlampieva, E. and Sukhishvili, S.A. (2006) Hydrogen-Bonded Layer-by-Layer Polymer Films. Journal of Macromolecular Science, Part C: Polymer Reviews, 46, 377-395. http://dx.doi.org/10.1080/15583720600945386

[44] Bosman, A.W., Sijbesma, R.P. and Meijer, E.W. (2004) Supramolecular Polymers at Work. Materials Today, 7, 34-39.

[45] Binder, W.H. (2005) Polymeric Ordering by H-Bonds. Mimicking Nature by Smart Building Blocks. Monatshefte fur Chemie, 136, 1-19.

[46] Haggman, L., Lindblad, C., Oskarsson, H., Ullström, A.-S. and Persson, I. (2003) The Influence of Short Strong Hydrogen Bonding on the Structure and the Physicochemical Properties of Alkyl-N-Iminodiacetic Acids in Solid State and Aqueous Systems. Journal of the American Chemical Society, 125, 3631-3641. http://dx.doi.org/10.1021/ja021012i

[47] Bailey, F.E., Lindberg, R.D. and Callard, R.W. (1964) Some Factors Affecting the Molecular Association of Poly(ethylene oxide) and Poly(acrylic acid) in Aqueous Solution. Journal of Polymer Science Part A: General Papers, 2, 845-851. http://dx.doi.org/10.1002/pol.1964.100020221

[48] Ikawa, T., Abe, K., Honda, K. and Tsuchida, E. (1975) Interpolymer Complex between Poly(ethylene oxide) and Poly(carboxylic acid). Journal of Polymer Science: Polymer Chemistry Edition, 13, 1505-1514. http://dx.doi.org/10.1002/pol.1975.170130703

[49] Bekturov, E.A. and Bimendina, L.A. (1981) Interpolymer Complexes. Advances in Polymer Science, 41, 99-147.

[50] Tsuchida, E. and Abe, K. (1982) Interactions between Macromolecules in Solution and Intermacromolecular Complexes. Advances in Polymer Science, 45, 1-126. http://dx.doi.org/10.1007/BFb0017549

[51] Hong, J.-D., Decher, G. and Schmitt, J. (1992) Buildup of Ultrathin Multilayer Films by a Self-Assembly Process: III. Consecutively Alternating Adsorption of Anionic and Cationic Polyelectrolytes on Charged Surfaces. Thin Solid Films, 210-211, 831-835. http://dx.doi.org/10.1016/0040-6090(92)90417-A

[52] Decher, G. (1997) Fuzzy Nanoassemblies: Toward Layered Polymeric Multicomposites. Science, 277, 1232-1237. http://dx.doi.org/10.1126/science.277.5330.1232

[53] Bertrand, P., Jonas, A., Laschewsky, A. and Legras, R. (2000) Ultrathin Polymer Coatings by Complexation of Polyelectrolytes at Interfaces: Suitable Materials, Structure and Properties. Macromolecular Rapid Communications, 21, 319-348. http://dx.doi.org/10.1002/(SICI)1521-3927(20000401)21:7<319::AID-MARC319>3.0.CO;2-7

[54] Kotov, N.A. (1999) Layer-by-Layer Self-Assembly: The Contribution of Hydrophobic Interactions. Nanostructured Materials, 12, 789-796. http://dx.doi.org/10.1016/S0965-9773(99)00237-8

[55] Clark, S.L. and Hammond, P.L. (2000) The Role of Secondary Interactions in Selective Electrostatic Multilayer Deposition. Langmuir, 16, 10206-10214. http://dx.doi.org/10.1021/la000418a

[56] Stockton, W. and Rubner, M. (1997) Molecular-Level Processing of Conjugated Polymers. 4. Layer-by-Layer Manipulation of Polyaniline via Hydrogen-Bonding Interactions. Macromolecules, 30, 2717-2725. http://dx.doi.org/10.1021/ma9700486

[57] Benjamin, I., Hong, H., Avny, Y., Davidov, D. and Neumann, R. (1998) Poly(phenylenevinylene) Analogs with Ring Substituted Polar Side Chains and Their Use in the Formation of Hydrogen Bonding Based Self-Assembled Multilayers. Journal of Materials Chemistry, 8, 919-924. http://dx.doi.org/10.1039/a707365h 
[58] Wang, L.Y., Wang, Z.Q., Zhang, X., Shen, J.C., Chi, L. and Fuchs, H. (1997) A New Approach for the Fabrication of an Alternating Multilayer Film of Poly(4-vinylpyridine) and Poly(acrylic acid) Based on Hydrogen Bonding. Macromolecular Rapid Communications, 18, 509-514. http://dx.doi.org/10.1002/marc.1997.030180609

[59] Wang, L., Fu, Y., Cui, S., Wang, Z., Zhang, X., Jiang, M., Chi, L. and Fuchs, H. (2000) Multilayer Assemblies of Copolymer PSOH and PVP on the Basis of Hydrogen Bonding. Langmuir, 16, 10490-10494. http://dx.doi.org/10.1021/la000733x

[60] Serizawa, T., Kamimura, S., Kawanishi, N. and Akashi, M. (2002) Layer-by-Layer Assembly of Poly(vinyl alcohol) and Hydrophobic Polymers Based on Their Physical Adsorption on Surfaces. Langmuir, 18, 8381-8385. http://dx.doi.org/10.1021/la0204491

[61] Zhang, H., Wang, Z., Zhang, Y. and Zhang, X. (2004) Hydrogen-Bonding-Directed Layer-by-Layer Assembly of Poly(4-vinylpyridine) and Poly(4-vinylphenol): Effect of Solvent Composition on Multilayer Buildup. Langmuir, 20, 9366-9370. http://dx.doi.org/10.1021/la048685u

[62] Fu, Y., Bai, S., Cui, S., Qiu, D., Wang, Z. and Zhang, X. (2002) Hydrogen-Bonding-Directed Layer-by-Layer Multilayer Assembly: Reconformation Yielding Microporous Films. Macromolecules, 35, 9451-9458. http://dx.doi.org/10.1021/ma0207881

[63] Bai, S., Wang, Z. and Zhang, X. (2004) Hydrogen-Bonding-Directed Layer-by-Layer Films: Effect of Electrostatic Interaction on the Microporous Morphology Variation. Langmuir, 20, 11828-11832. http://dx.doi.org/10.1021/la047968j

[64] Zhang, H., Fu, Y., Wang, D., Wang, L., Wang, Z. and Zhang, X. (2003) Hydrogen-Bonding-Directed Layer-by-Layer Assembly of Dendrimer and Poly(4-vinylpyridine) and Micropore Formation by Post-Base Treatment. Langmuir, 19, 8497-8502. http://dx.doi.org/10.1021/la035036u

[65] Sukhishvili, S.A. and Granick, S. (2000) Layered, Erasable, Ultrathin Polymer Films. Journal of the American Chemical Society, 122, 9550-9551. http://dx.doi.org/10.1021/ja002410t

[66] Sukhishvili, S.A. and Granick, S. (2002) Layered, Erasable Polymer Multilayers Formed by Hydrogen-Bonded Sequential Self-Assembly. Macromolecules, 35, 301-310. http://dx.doi.org/10.1021/ma011346c

[67] Hammond, P.T. (2004) Form and Function in Multilayer Assembly: New Applications at the Nanoscale. Advanced Materials, 16, 1271-1293. http://dx.doi.org/10.1002/adma.200400760

[68] Wood, K.C., et al. (2007) Methods of Making Decomposable Thin Films of Polyelectrolytes and Uses Thereof. US Patent Application 2007/0020469.

[69] Kharlampieva, E. and Sukhishvili, S.A. (2003) Ionization and pH Stability of Multilayers Formed by Self-Assembly of Weak Polyelectrolytes. Langmuir, 19, 1235-1243. http://dx.doi.org/10.1021/la026546b

[70] Kharlampieva, E., Ankner, J.F., Rubinstein, M. and Sukhishvil, S.A. (2008) pH-Induced Release of Polyanions from Multilayer Films. Physical Review Letters, 100, Article ID: 128303.

http://dx.doi.org/10.1103/PhysRevLett.100.128303

[71] Tredgold, R. (1994) Order in Thin Organic Films. Cambridge University Press, Cambridge.

[72] Lvov, Y.M. and Decher, G. (1994) Assembly of Multilayer Ordered Films by Alternating Adsorption of Oppositely Charged Macromolecules. Crystallography Reports, 39, 628-647.

[73] Tsukruk, V.V. and Janietz, D. (1996) Interfacial Gradient of Molecular Ordering in Organized Films of a Liquid Crystalline Discotic Polymer. Langmuir, 12, 2825-2829. http://dx.doi.org/10.1021/la951055v

[74] Tsukruk, V.V., Bliznyuk, V.N. and Visser, D. (1997) Electrostatic Deposition of Polyionic Monolayers on Charged Surfaces. Macromolecules, 30, 6615-6625. http://dx.doi.org/10.1021/ma961897g 